Journal of Transformative Praxis

Vol. 1, No. 1, 2020, pp. 1-8

\title{
Editorial
}

\section{Conceptualising Transformative Praxis}

\section{Bal Chandra Luitel and Niroj Dahal}

Kathmandu University School of Education, Department of STEAM Education, Hattiban, Lalitpur, Nepal

Email: bcluitel@kusoed.edu.np and niroj@kusoed.edu.np

0000-0002-5483-2385,

0000-0001-7646-1186

\begin{abstract}
Transformative praxis covers a wide range of scholarly pursuits for social change via reflexive research and practice. Praxis is used to raise the consciousness of researchers, participants and social actors through a constant embracing of a critical stance toward text, discourse, and the lifeworld. A host of images are used to conceptualise the notion of transformative praxis as epistemology, theory, methodology, professional development, genres and logics, and empowerment. Transformative praxis as epistemology refers to multiple ways of knowing embedded in critiquing, reconceptualizing self, and envisioning; whereas transformative praxis as theory is informed by the critical scholarship of strengths and limitations of theories, philosophies, and perspectives as a means for social change. Our ideas of transformative praxis as methodology are embedded in the commitments of researchers and practitioners to engage in the process of holistic meaning making. Reflexive engagement of researchers and practitioners in the lifeworld contributes to the conceptualisation of transformative praxis as professional development. Transformative praxis as empowerment draws upon the ongoing discourse of an emancipatory interest that emphasises autonomy, responsibility, and criticality. The articles in this issue focus on developing cosmologically responsible educational processes, deviance as pedagogical action, holistic learning, and pedagogical change through multiparadigmatic research processes.
\end{abstract}

Keywords: Praxis. Logics and genres. Reflexivity. Emancipation.

\section{Introduction}

Our notion of transformative praxis covers a wide range of scholarly pursuits of social change, such as developing educational programs, addressing humanitarian crises, and implementing culturally responsible pedagogies (Navarro, 2018). Methodologically, transformative praxis aligns with reflexive research traditions arising from participatory action research, arts-based research, transformative mixed methods, critical policy research, narrative research, and autoethnographic inquiry, to name but a few. In these methodologies, 
praxis is used to raise the consciousness of researchers, participants and actors by following a sequence of actions and critical reflections (Maseko, 2018). The goal of such research methodologies is not only to find answers but to gain insights into processes and outcomes of research and practice through critical and reflective knowledge production. Transformative praxis is thus characterized by recursive "reflections and action upon the world in order to transform it" (Freire, 2005, p. 36). Owing to the great diversity of contexts, practices and people, there is no single and prescribed technique for transformative praxis, apart from the goal of cultivating the critical conscience of researchers, practitioners, participants and actors through ethical and participatory engagement in the lifeworld. Developing transformative praxis demands a constant need to embrace a critical stance toward text, discourse, and the lifeworld to change our practices and systems in favour of social justice, equity, and inclusion (Hyslop-Margison \& Dale, 2010). We hold the view that practitioners with transformative sensibilities play a crucial role in examining their own beliefs, assumptions, and activities to improve their actions for creating better systems and practices (Berryman, 2013). Active engagement and dialogue with fellow members of the community of practice is the first necessary step for transformative praxis (Pillay, 2015). Developing a sense of agency and collegiality among members of the community of practice contributes to the sustenance of the process of transformative praxis, which is akin to change through a sequence of action and critical reflection. In this way, the process leads toward an envisioning of existing practices in the direction of promoting socially just and equitable systems (Maseko, 2018). As the notion of transformative praxis for both researchers and practitioners cannot simply be reduced to discrete action and reflection, this editorial discusses the notion via the following images of transformative praxis as/for epistemology, theory, methodology, professional development, genres and logics, and empowerment.

\section{Epistemology}

For us, the Journal is grounded in the idea of multiple ways of knowing, such as critiquing, reconceptualizing self, and envisioning (Luitel, 2018). The epistemic metaphor of critiquing enables researchers and practitioners to explore disempowering practices, cultures, and systems present in self and others. The idea of transformative praxis as epistemology is further enhanced by the image of knowing as reconceptualizing self which puts primacy on examining the deep-seated values, beliefs, and perceptions of researchers and practitioners, with a view to morph their situatedness as change agents. This examination allows a cognitive-aesthetic shift from practitioners and researchers as passive consumers of metanarratives to active artist creators of inclusive social realities (Granger, 2006; Mukhopadhyay, 2019). The epistemic metaphor of knowing as envisioning allows researchers and practitioners to imagine inclusive and empowering futures through a humane approach to establishing an active connection between the transpired, ongoing, and emergent. We echo Maxine Greene's idea that such imagining would not be error-free, for an active exercise of vision making is less about error and more about our commitment to change (Greene, 1995).

\section{Theory}

Our formulation of transformative praxis as theory draws upon the critical scholarship of the strengths and limitations of theories, philosophies, and perspectives in the engagement of researchers and practitioners in the realization of the transformative potential of their research and practice (Rahmawati \& Taylor, 2015). The conventional notion of theory as a framework is contested by a hermeneutic perspective of theory as referent (Tobin \& Tippins, 1993). The 
shift from framework to referent is indicative of the limitations of theory and practice. Likewise, transformative praxis as theory can be better described by the idea of radical fallibilism, for the nature of theoretical conceptions, categories and classifications is transient, imperfect, and subject to revisability, such as the theorems and proofs of mathematics (Ernest, 2016). Our notion of transformative praxis is premised upon the notion that changedriven initiatives are less likely to work under the guise of an absolutist vision of the world.

Theory, therefore, is not only for the purpose of describing the world, but is also about taking a stance, making a commitment to change, and engaging consciously in the lifeworld of self and others. A transformative activist stance is less about texts and ideas as Eidos, than it is about the dynamic interplay between texts and lifeworld, very much akin to dialectically reconstructing the perspective embedded in one's own research and practice (Stetsenko, 2017). Such an emergent nature of theory can be validated better by the lived experience of those who are part of the research and practice. Such a dynamic validation process, as Jack Whitehead (2009) succinctly says, is an act of developing one's own living educational theory.

\section{Methodology}

Our idea of transformative praxis as methodology is embedded in the commitment of researchers and practitioners to engage in a process of meaning-making that contributes to create socially just, empowering, and inclusive systems and practices (Luitel \& Taylor, 2011). The limitations of humanistic methodologies are well documented in recent publications that call for post and multiparadigmatic designs to ensure both rationalistic and postrationalistic approaches become systemic (Andrew, 2017). This systematicity is informed by the dialectics of givens and emergent, such as evidences and meanings, pre-specified protocols and nascent relations, observers and actors, and prescriptive and negotiated standards. The core of this dialectics is the desire to use a jazz metaphor in creating an empowering (i.e., inclusive, equitable, and participative) environment for most, if not all, to contribute to generating meanings and models (Denzin et al., 2017). Thus, researchers and practitioners engage in new language games that ensure the capturing of evidences that are only limitedly accounted for through processes grounded in the hypothetico-deductive system. For example, the exclusive use of the language of data might not help to capture the voices of the field of engagements by researchers and practitioners. The idea of research subjects and informants presents a very limited view of others whom researchers and practitioners engage with in making sense of the lifeworld. Instead, our view of transformative praxis as methodology considers others as collaborators, participants, and actors in contributing to our individual and collective sensemaking of the lifeworld. An exclusively rationalistic approach to sensemaking through analytical and deductive methods is insufficient for capturing dynamic realities informed by the interplay of data and voices, senses and emotions, descriptions and visions, perceptions and feelings, analytical and ethical, and minds and bodies, to name but a few (Denzin, 2019). Doubting the Enlightenment ideal that humans (with their rational faculties) are the only species capable of generating knowledge, this posthumanist shift enables researchers and practitioners to become mindful of ecologies that can contribute to the process of making sense of the world (Cudworth \& Hobden, 2017).

\section{Professional Development}

Given the reflexive engagement of researchers and practitioners in the lifeworld, we hold the view that transformative praxis contributes to the professional development of researchers 
and practitioners through critical reflection on both self and other's values, beliefs and practices. Practitioners can use different forms of reflection, such as retrospective, ongoing, and anticipatory (Johns, 2017). Retrospective reflection refers to reflection on events, activities and performativities accomplished in the past. The main purpose of such reflection is to examine events that have transpired from the vantage point of new possibilities. Reflection on our ongoing actions can help immediately improve, revise, and modify our activities and engagement in the world (Brookfield, 2017). Such an approach to reflection-inaction makes practitioners mindful of ongoing events and eventualities. In the same manner, anticipatory reflection enables practitioners to envision into possible opportunities and challenges embedded in their practice.

Research processes informed by critical reflexivity enable researchers to engage deeply in examining self and others' values, assumptions, beliefs, and practices. This reflexive process, for us, is further enhanced by the researcher's orientation of research as/for learning in which the subject of learning becomes how the researcher's convictions, actions, and positionality contribute to imagining socially just, inclusionary, and equitable practices and systems. A persistent reflection on power relations between researchers and participants enables them to embody transformative sensibilities in their thinking and actions (Brookfield, 2008). In recent times the power relations between humans and the natural environment have become a subject of critical reflection, as privileging humans over other species has endangered Mother Earth.

\section{Inclusive Genres and Logics}

With the advent of the Enlightenment project, the use of linear (c.f., nonlinear), clean (c.f., messy), dualistic (c.f., dialectical), and prescriptive (c.f., perspectival) modes of thinking and representation have been commonplace in social and educational research, thereby reducing the chance of engaging researchers and practitioners in deep, embodied, and intimate voices and visions about their research and practice (Saldana, 2018). Embedded in such modes of thinking and representation is the hypothetico-deductive system that puts primacy on deductive (i.e., based on linear certainty through pre-existing premises), analytical (i.e., based on the dualism of right and wrong), and propositional (i.e., based on prescriptive causation) logics and genres (Luitel \& Taylor, 2013). These exclusionary logics and genres promote a technical rationality that offers only a limited opportunity to exercise, embody and showcase much-needed praxis in researchers' and practitioners' engagements for empowering, just, and equitable systems and practices (Taylor \& Luitel, 2019).

The void created by the Enlightenment project in exercising, embodying, and portraying transformative praxis can be filled by a combination of conventional and inclusionary logics and genres, including metaphorical, dialectical, poetic, and narrative. Metaphors are used to unpack conceptual complexity and subtlety embedded in the lifeworld, conceptual systems, and structures. Oftentimes, metaphors are mistakenly taken as a rhetorical device rather than our embodied conceptual systems that are connected through an allegorical, analogical, proverbial, mythical, and ecological system of thought. Various forms of dialectics (e.g., here and there, up and down, past and present, theory and practice) are constitutive of social realities, although they have been mistakenly used as binary opposites in the conventional use of logic and genre. Dialectical logic imagines realities resulting from a dynamic interplay between so-called opposing categories as, for example, theory cannot be conceived without practice and vice-versa (Taylor, 2013).

Poetic logics and genres are used to represent nonlinearity, ineffability and subtlety embedded in the praxis of researchers and practitioners as change agents (Faulkner, 2007). The undue privilege of linearity in thinking and representation has been an obstacle to 
unpacking the messiness of our lifeworld. Likewise, the standard academic language of the plain, cut-and-dried, and impersonal genre does not enable researchers and practitioners to represent that which cannot be expressed. Poetic logics and genres are useful for researchers and practitioners to bring forth the subtilities of power, privilege and hegemony (Faulkner, 2016). Narrative logics and genres are used to bring forth contextual accounts arising from our actions (and inactions) in the lifeworld. Such accounts can be categorised as resistant, healing, and advocacy. Resistant narratives develop an oppositional stance as a recourse for creating narrative visions of enabling societies. Narratives that heal people in difficulties can be cathartic for those who have gone through sufferings of different kinds. Likewise, narrative logics and genres are also used to envision an inclusive, equitable, and empowering social systems and practices (Sjollema \& Bilotta, 2017).

\section{Empowerment}

Transformative praxis as empowerment draws on the ongoing discourse of the emancipatory interest that emphasises autonomy, responsibility and criticality (Kincheloe \& Pinar, 1991). The notion of autonomy is conceptualised as an outcome of the process of the critical reflective ability of practitioners, researchers, and people in their relations with colleagues and participants. The process of reflecting on self is not only cognitive but also an act of turning ego onto itself, very much akin to the convictional and actional form of engagements (Maseko, 2018). In this way, the chance of an individual acting on whim and habituated compulsion is greatly lessened. Responsibility is connected with the process of becoming an autonomous agent who takes charge of what he or she has committed to. Here, commitment refers to one's willingness and readiness to act as a change agent in the context of research and practice. However, there might be dangers associated with change agents embracing a paternalistic approach to dealing with participants and actors. The cure can be found in maintaining a well-developed criticality embedded in the process and outcomes of research and practice. Disciplines, structures and models are critiqued for their limitedness in harnessing justice, equity, and empowerment. In this way, empowerment becomes a multidimensional social process that helps gain control over our practices by questioning takenfor-granted assumptions and frames of reference, and generating more empowering beliefs and informed actions (Luitel \& Taylor, 2011). Transformative praxis enables practitioners and researchers to act as change agents who raise the consciousness of the self and others through acts of critical reflection.

\section{The Inaugural Issue}

This inaugural issue of the Journal includes four original articles that make cases for socially and cosmologically responsible educational processes, positive deviance as/for insubordination in the educational process, holistic orientation for transformative learning, critical reflection as research, and self-culture dialectics as/for raising consciousness.

Varghese envisages how teaching and learning processes need to be connected with the cosmos while teaching and learning mathematics. Subscribing to critical autoethnography, the discussion focuses on why and how mathematics teaching and learning needs to take into consideration our relationship and responsibility towards the natural environment and the cosmos as a means for making educational processes cosmologically responsible. Taking his lived experiences as 'data' and reflective meaning-making as 'analysis', Varghese looks into his life as a student in school and university days, as a Jesuit, as a teacher and as a student, thereby reflecting the shortfalls of culturally and cosmologically decontextualised educational processes. Likewise, he reflects on his relationship with the 
cosmos, which challenges a materialistic educational system that lacks responsibility towards the environment and cosmos. The author promotes his vision of establishing connections between curricular topics and cosmological issues to raise awareness in students for caring for the cosmos.

Orey and Rosa discuss the concept of positive deviance concerning the research program of ethnomathematics. Ethnomathematics as a pedagogical action helps students to overcome the use of disassociated techniques that are often blindly memorised. They discuss the notion of positive deviance as a means for pedagogical actions that deal with content often disconnected from the reality of the students. They highlight the importance of analysing the relation between culture and mathematics by questioning the predominant view of mainstream mathematics as culture-neutral and diversifying teaching strategies. Their discussion of 'insubordination' triggered by ethnomathematics enables practitioners and researchers to adopt positive deviance in developing pedagogical actions to connect mathematics with reality. They conclude that positive deviance can be considered as combat against the dehumanizing effects of curricular and bureaucratic subordination. Ethnomathematics can allow practitioners and researchers to develop innovative pedagogies that help students to unpack their sociocultural and academic potential, through a diversity of teaching strategies used in the mathematics curriculum.

Ojha makes a case for holistic orientation by discussing concepts associated with transformative learning, including reflective practice as a means for developing educators' perceptions of holistic education. Further, he argues that educators with holistic orientations emphasise inner lives, balance, interconnections, trustful and authentic relationships, dialogue, and concern and care for others in their pedagogical practices. Ojha's descriptive insights into pedagogical reflections of teachers exemplify holistic orientations as a potentially practical strategy for transformative learning. The article concludes with the note that the role of an educator is to explore their own essences by acquainting practitioners with various paths and possibilities. Teachers as practitioners are encouraged to recreate holistic learning contexts that potentially promote transformative learning.

Luitel charts his transformative research journey by reflecting on his experiences of the process of learning and teaching in mathematics. Guided by autoethnography as methodology, Luitel's reflections are useful for other researchers and practitioners wishing to reflect on the strengths and limitations of learning and teaching activities in their contexts, thereby envisioning more inclusive practices for the future. Subscribing to critical selfreflection on his professional praxis as a teacher, researcher and educator, Luitel questions self and others in terms of how they can work to solve issues of disengagement in the mathematics curriculum, pedagogy and assessment to improve the landscape of mathematics education for social justice, inclusion and empowerment. The Habermasian knowledge constitutive interests (i.e., technical, practical, and emancipatory) and Schubert's curriculum images (i.e., content or subject matter, experiences, cultural reproduction, etc.) are theoretical referents used to interrogate the researcher's experiences of doing and learning mathematics as a mathematics teacher and practitioner-researcher.

\section{List of References}

Andrew, B. (2017). Climate change, migration, and the crisis of humanism. Wiley

Interdisciplinary Reviews: Climate Change, 8(3), e460. https://doi.org/10.1002/wcc.460

Berryman, M. (2013). Culturally responsive pedagogies as transformative praxis. Waikato Journal of Education, 18(2). 
Brookfield, S. (2008). Radical questioning on the long walk to freedom: Nelson Mandela and the practice of critical reflection. Adult Education Quarterly, 58(2), 95.

Brookfield, S. D. (2017). Becoming a critically reflective teacher. John Wiley \& Sons.

Cudworth, E., \& Hobden, S. (2017). The emancipatory project of posthumanism. Routledge.

Denzin, N. K. (2019). The death of data in neoliberal times. Qualitative Inquiry, 25(8), 721724.

Denzin, N. K., Lincoln, Y. S., MacLure, M., Otterstad, A. M., Torrance, H., Cannella, G. S., Koro-Ljungberg, M., \& McTier, T. (2017). Critical qualitative methodologies: Reconceptualizations and emergent construction. International Review of Qualitative Research, 10(4), 482-498.

Ernest, P. (2016). The problem of certainty in mathematics. Educational Studies in Mathematics, 92(3), 379-393.

Faulkner, S. L. (2007). Concern with craft: Using ars poetica as criteria for reading research poetry. Qualitative Inquiry, 13(2), 218-234. https://doi.org/10.1177/1077800406295636

Faulkner, S. L. (2016). Poetry as method: Reporting research through verse. Routledge.

Freire, P. (2005). Education for critical consciousness. Continuum.

Granger, D. A. (2006). John Dewey, Robert Pirsig, and the art of living: Revisioning aesthetic education. Springer.

Greene, M. (1995). Releasing the imagination: Essays on education, the arts, and social change. Jossey-Bass.

Hyslop-Margison, E. J., \& Dale, J. (2010). Paulo Freire: Teaching for freedom and transformation. Springer.

Johns, C. (Ed.). (2017). Becoming a reflective practitioner. John Wiley \& Sons.

Kincheloe, J. L., \& Pinar, W. (Eds.). (1991). Curriculum as social psychoanalysis: The significance of place (pp. 1-23). State University of New York Press.

Luitel, B. C. (2018). A mindful inquiry towards transformative curriculum vision for inclusive mathematics education. Learning: Research and Practice, 4(1), 78-90. https://doi.org/0.1080/23735082.2018.1428141

Luitel, B. C., \& Taylor, P. C. (2011). Kincheloe's bricolage. In K.G. Tobin (Ed.), Key works in critical pedagogy:Joe Kincheloe (pp. 191-199). Brill Sense.

Luitel, B. C., \& Taylor, P. C. (2013). Fractals of 'old'and 'new'logics: A post/modern proposal for transformative mathematics pedagogy. Philosophy of Mathematics Education Journal, 27, 1-31.

Maseko, P. N. (2018). Transformative praxis through critical consciousness: A conceptual exploration of a decolonial access with success agenda. Educational Research for Social Change, 7(Special Issue), 78-90.

Mukhopadhyay, A. (2019). Everyday aesthetics and the Indic Goddess traditions: An Aurobindonian approach. Journal of Comparative Literature and Aesthetics, 42(2), 48-59.

Navarro, O. (2018). We can't do this alone: Validating and inspiring social justice teaching through a community of transformative praxis. Curriculum Inquiry, 48(3), 335-358.

Pillay, A. (2015). Transformative and critical education praxis in a teacher education lecture room. Education as Change, 19(3), 4-23.

Rahmawati, Y., \& Taylor, P. C. (2015). Moments of critical realisation and appreciation: A transformative chemistry teacher reflects. Reflective Practice, 16(1), 31-42.

Saldana, J. (2018). Writing qualitatively: The selected works of Johnny Saldaña. Routledge.

Sjollema, S. D., \& Bilotta, N. (2017). The raw and the poignant: Using community poetry in research. Journal of Poetry Therapy, 30(1), 17-32. 
Stetsenko, A. (2017). The transformative mind: Expanding Vygotsky's approach to development and education. Cambridge University Press.

Taylor, P. C., \& Luitel, B. C. (Eds.). (2019). Research as transformative learning for sustainable futures: Glocal voices and visions. Brill Sense.

Taylor, P.C. (2013). Research as transformative learning for meaning-centred professional development. In O. Kovbasyuk \& P. Blessinger (Eds.), Meaning-centred education: International perspectives and explorations in higher education. Routledge.

Tobin, K., \& Tippins, D. (1993). Constructivism as a referent for teaching and learning. In K. Tobin. (Ed.), The practice of constructivism in science education (pp. 3-21). Lawrence Erlbaum.

Whitehead, J. (2009). Generating living theory and understanding in action research studies. Action Research, 7(1), 85-99.

\section{Suggested Citation:}

Luitel, B. C., \& Dahal, N. (2020). Conceptualising transformative praxis. Journal of Transformative Praxis, 1(1), 1-8. 